\title{
Volatile Metabolites in Liverworts of Ecuador
}

\author{
Eduardo Valarezo ${ }^{1, *(\mathbb{D})}$, Oswaldo Tandazo ${ }^{1}$, Kathia Galán ${ }^{1}$, Jandry Rosales ${ }^{1}$ and Ángel Benítez ${ }^{2}$ \\ 1 Departamento de Química y Ciencias Exactas, Universidad Técnica Particular de Loja, \\ San Cayetano Alto s/n, 110150 Loja, Ecuador; ortandazo@utpl.edu.ec (O.T.); \\ kcgalan@utpl.edu.ec (K.G.); jandryximena@gmail.com (J.R.) \\ 2 Departamento de Ciencias Biológicas, Universidad Técnica Particular de Loja, \\ San Cayetano Alto s/n, 110150 Loja, Ecuador; arbenitez@utpl.edu.ec \\ * Correspondence: bevalarezo@utpl.edu.ec
}

Received: 27 January 2020; Accepted: 24 February 2020; Published: 5 March 2020

check for updates

\begin{abstract}
Volatile metabolites from Frullania brasiliensis Raddi, Herbertus juniperoideus (Sw.) Grolle, Leptoscyphus hexagonus (Nees) Grolle, and Syzygiella anomala (Lindenb. \& Gottsche) Steph collected in the south of Ecuador were investigated. Volatile secondary metabolites were extracted by hydrodistillation and analyzed by gas chromatography/flame ionization detector (GC/FID) and Gas chromatography/Mass spectrometry (GC/MS). Sixty-seven volatile compounds were identified in the four species, which represent between $80.12-90.17 \%$ of the total chemical composition. The major components were $\tau$-muurolol $(32.14 \%)$ and Germacrene-D $(11.98 \%)$ in the essential oil of F. brasiliensis, bicyclogermacrene $(18.23 \%)$, and Caryophyllene oxide $(15.29 \%)$ in the oil of H. juniperoideus, Cabreuva oxide D (33.77\%) and Elemol (18.55\%) in the oil of Leptoscyphus hexagonus, and Silphiperfola-5,7(14)-diene (25.22\%) and Caryophyllene oxide (8.98\%) in the oil of Syzygiella anomala. This is the first report on volatile compounds for the species Herbertus juniperoideus, Leptoscyphus hexagonus, and Syzygiella anomala.
\end{abstract}

Keywords: bryophytes; foliose liverworts; secondary metabolites

\section{Introduction}

The Ecuador has a very rich liverworts flora over 770 species [1-3]. Liverworts produce secondary metabolites in abundance [4] with more than 1500 terpenoids and 350 aromatic compounds flavonoids [5-7]. In this context, liverworts produce terpenoids and aromatic compounds, many of which exhibit diverse, interesting biological properties related to antitumor, antimicrobial, antifungal, antioxidative, and insecticidal activities; cytotoxic and insect antifeedant [5]. Several studies have shown abundant secondary metabolites in foliose liverworts. For example, Asakawa et al. [8] studied by gas chromatography coupled to mass spectrometry (GC/MS) the volatile components of 25 taxa of the liverwort family Frullaniaceae from New Zealand, Australia and South America.

In addition, chemical constituents of Frullania serrata were isolated, and their structure was elucidated by nuclear magnetic resonance (1D- and 2D-NMR), high-resolution electrospray ionization mass spectrometry (HR-ESI-MS) and infrared spectroscopy (IR) [9]. The chemical composition of Frullania tamarisci essential oil was investigated using gas chromatography coupled to flame ionization detection (GC/FID), GC/MS, and NMR analyses [10]. Compounds of Frullania hamatiloba have been isolated and their structures were determined by a combination of the ${ }^{1} \mathrm{H}$ - and ${ }^{13} \mathrm{C}-\mathrm{NMR}, \mathrm{MS}$, ultraviolet-visible spectroscopy (UV), IR, and X-ray crystallographic (X-ray) analysis [11]. In another species of this genus, the F. brasiliensis two eremophilanolides were established by NMR and X-ray analysis [12].

On the other hand, chemical constituents from Herbertus subdentatus (Steph.) Fulford and $H$. acanthelius Spruce have been detected by ${ }^{1} \mathrm{H}$ - and ${ }^{13} \mathrm{C}-\mathrm{NMR}, \mathrm{UV}$, IR, thin-layer chromatography 
(TLC), and GC/MS [13]. In the family Lophocoleaceae, chemical constituents from Chiloscyphus pallidus (Mitt.) Engel \& Schuster [14], Heteroscyphus planus [15], and Heteroscyphus billardierei (Schwägr.) Schiffn. have been isolated and studied by GC/MS and NMR techniques [16]. Finally, secondary metabolites in the liverwort Syzygiella rubricaulis (Nees) Stephani has been analyzed by GC/MS [17].

In the Ecuador, liverworts are plants that produce a wide array of biologically active compounds [13], however, less than $3 \%$ of these compounds have been investigated. As it is recorded in the bibliography of the large number of existing liverworts species in Ecuador, there is a record of the study of the compounds from Frullania brasiliensis, Herbertus acanthelius, Herbertus subdentatus, Plagiochila alternans Lindenb. \& Gottsche, Plagiochila micropterys Gottsche, Macrolejeunea pallescens (Mitt.) Schiffn., Marchantia plicata Nees \& Mont. [13], Marchesinia brachiate (Sw.) Schiffn. [18], Noteroclada confluens Taylor, Symphyogyna brasiliensis Nees \& Mont. [19], and Syzygiella rubricaulis (Nees) Stephani [17].

The purpose of the present investigation was the isolation and identification of volatile metabolites of four species of liverworts from Ecuador, three of which, Herbertus juniperoideus, Leptoscyphus hexagonus, and Syzygiella anomala, do not have previous chemical or phytochemical studies.

\section{Results}

\subsection{Volatile Compounds Isolation}

By means of hydrodistillation in a Clevenger-type apparatus, $0.3 \mathrm{~mL}$ of essential oil was obtained from $1500 \mathrm{~g}$ of Frullania brasiliensis, what represents a yield of $0.02 \%(v / w)$. For the species Herbertus juniperinus, Leptoscyphus hexagonus, and Syzygiella anomala, yields close to $0.01 \%$ (v/w) were obtained.

\subsection{Volatile Compounds Identification}

The identification of volatile compounds present in liverworts of Ecuador was carried out by means of gas chromatography equipped with a flame ionization detector (GC/FID) and gas chromatography coupled to a mass spectrometer detector (GC/MS) using capillary nonpolar column DB-5ms. To our knowledge, this is the first report on the chemical composition of volatile compounds from Herbertus juniperinus, Leptoscyphus hexagonus, and Syzygiella anomala (Table 1). In total, sixty-seven chemical constituents were identified in essential oil samples, representing $80.12-90.17 \%$ of the total composition. These constituents were grouped into monoterpene hydrocarbons $(0.14 \%)$, oxygenated monoterpenes (0.79-1.16\%), sesquiterpene hydrocarbons (19.61-65.39\%), oxygenated sesquiterpenes (23.48-66.24\%), diterpene hydrocarbons $(0.23-0.87 \%)$, and other compounds $(0.76-1.16 \%)$.

Table 1. Volatile metabolites of Frullania brasiliensis (Fb), Herbertus juniperinus ( $\mathrm{Hj})$, Leptoscyphus hexagonus (Lh), and Syzygiella anomala (Sa).

\begin{tabular}{|c|c|c|c|c|c|c|c|c|c|c|}
\hline Peak $\mathbf{N}^{\circ}$ & Compound ${ }^{a, b}$ & RI & $\mathrm{RI}^{\text {ref }}$ & $\mathbf{F b}$ & $\mathbf{H j}$ & Lh & Sa & Type & CF & MM (Da) \\
\hline 1 & $\beta$-Phellandrene & 1023 & 1025 & - & - & - & 0.14 & MH & $\mathrm{C}_{10} \mathrm{H}_{16}$ & 136.13 \\
\hline 2 & 1-Octen-3-ol, acetate & 1107 & 1110 & 0.45 & 0.79 & - & 1.16 & $\mathrm{OM}$ & $\mathrm{C}_{10} \mathrm{H}_{18} \mathrm{O}_{2}$ & 170.13 \\
\hline 3 & Thymol methyl ether & 1217 & 1232 & 1.16 & - & - & - & OT & $\mathrm{C}_{11} \mathrm{H}_{16} \mathrm{O}$ & 164.12 \\
\hline 4 & Bicycloelemene & 1321 & 1331 & - & 0.33 & - & 0.23 & $\mathrm{SH}$ & $\mathrm{C}_{15} \mathrm{H}_{24}$ & 204.19 \\
\hline 5 & $\delta$-Elemene & 1324 & 1335 & 0.10 & - & - & - & $\mathrm{SH}$ & $\mathrm{C}_{15} \mathrm{H}_{24}$ & 204.19 \\
\hline 6 & $\alpha$-Cubebene & 1335 & 1345 & 0.42 & 0.15 & - & - & $\mathrm{SH}$ & $\mathrm{C}_{15} \mathrm{H}_{24}$ & 204.19 \\
\hline 7 & Silphiperfola-5,7(14)-diene & 1355 & 1363 & 0.25 & - & - & 25.22 & $\mathrm{SH}$ & $\mathrm{C}_{15} \mathrm{H}_{22}$ & 202.17 \\
\hline 8 & Isoledene & 1358 & 1374 & - & - & - & 0.10 & $\mathrm{SH}$ & $\mathrm{C}_{15} \mathrm{H}_{24}$ & 204.19 \\
\hline 9 & $\alpha$-Copaene & 1363 & 1374 & 0.44 & 0.27 & 0.68 & - & $\mathrm{SH}$ & $\mathrm{C}_{15} \mathrm{H}_{24}$ & 204.19 \\
\hline 10 & $\beta$-Bourbonene & 1370 & 1387 & 0.74 & 0.32 & - & - & $\mathrm{SH}$ & $\mathrm{C}_{15} \mathrm{H}_{24}$ & 204.19 \\
\hline 11 & $\beta$-Elemene & 1383 & 1389 & 3.03 & 0.78 & - & - & $\mathrm{SH}$ & $\mathrm{C}_{15} \mathrm{H}_{24}$ & 204.19 \\
\hline 12 & Longifolene & 1392 & 1407 & 1.77 & 2.58 & 0.33 & - & $\mathrm{SH}$ & $\mathrm{C}_{15} \mathrm{H}_{24}$ & 204.19 \\
\hline 13 & $\beta$-Cubebene & 1393 & 1387 & 0,63 & - & - & - & $\mathrm{SH}$ & $\mathrm{C}_{15} \mathrm{H}_{24}$ & 204.19 \\
\hline 14 & $\alpha$-Longipinene & 1399 & 1350 & - & - & 3.62 & - & $\mathrm{SH}$ & $\mathrm{C}_{15} \mathrm{H}_{24}$ & 204.19 \\
\hline 15 & $\alpha$-Gurjunene & 1412 & 1409 & - & 1.15 & - & 0.73 & $\mathrm{SH}$ & $\mathrm{C}_{15} \mathrm{H}_{24}$ & 204.19 \\
\hline 16 & Caryophyllene & 1412 & 1417 & - & - & 0.22 & 0.10 & $\mathrm{SH}$ & $\mathrm{C}_{15} \mathrm{H}_{24}$ & 204.19 \\
\hline 17 & Aromandendrene & 1423 & 1439 & 1.07 & 1.61 & 0.34 & - & $\mathrm{SH}$ & $\mathrm{C}_{15} \mathrm{H}_{24}$ & 204.19 \\
\hline
\end{tabular}


Table 1. Cont.

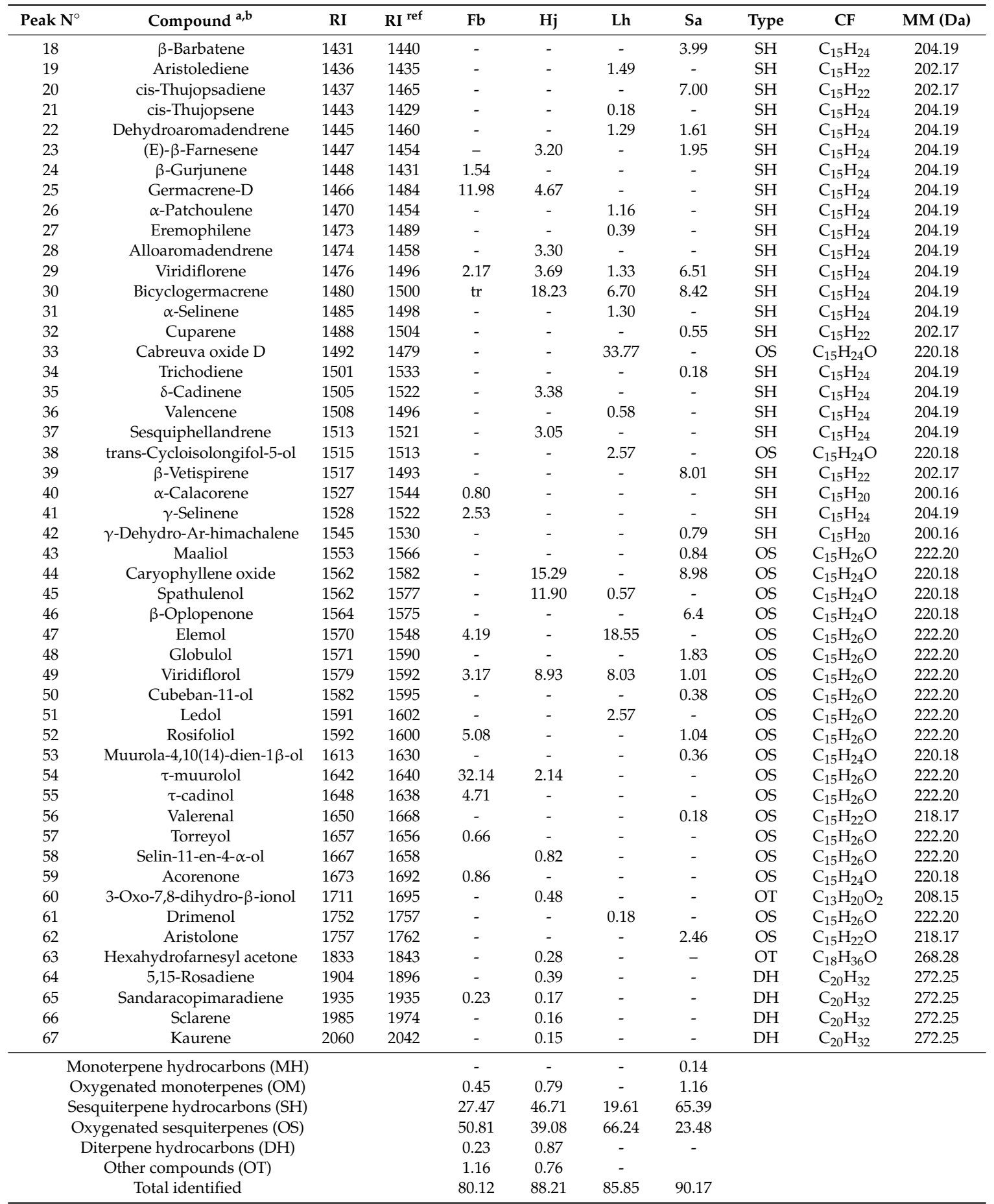

${ }^{a}$ Compounds ordered according to the elution order in the column DB5-Ms. ${ }^{b}$ All compounds were identified by MS and RI: MS, by comparison of the mass spectrum with those of the computer mass libraries Wiley 7, Adams 21 and NIST 05 22; RI, by comparison of RI with those reported in the literature; 21,22 , and 23. tr, trace $(<0.05 \%)$; -, not detected; RI, retention indices in the a-polar column (DB5-MS); $\mathrm{RI}^{\mathrm{ref}}$, references: 21,22 , and 23 . CF, Chemical Formula; MM, Monoisotopic mass.

Twenty-seven components were determined in essential oil of H. juniperinus, representing $88.21 \%$ of the total oil, the principal constituents are found to be sesquiterpene hydrocarbons: bicyclogermacrene $(18.23 \%)$ and germacrene-D (4.67\%) and oxygenated sesquiterpene: caryophyllene oxide $(15.29 \%)$, spathulenol $(11.90 \%)$ and viridiflorol $(8.93 \%)$. Twenty-one components were identified for the essential oil of L. hexagonus, representing $85.85 \%$ of the total oil, the principal group was oxygenated 
sesquiterpenes such as cabreuva oxide D (33.77\%), Elemol (18.55\%) and Viridiflorol (8.03\%) and sesquiterpene hydrocarbons like bicyclogermacrene (6.70\%). T-muurolol (32.14\%), germacrene-D $(11.98 \%)$, Rosifoliol $(5.08 \%)$, $\tau$-cadinol $(4.71 \%)$ and elemol $(4.19 \%)$ were the main compounds of F. brasiliensis out of Twenty-five components, representing $80.12 \%$ of the total essential oil.

In essential oils of $F$. brasiliensis the principal groups were oxygenated sesquiterpenes (50.81\%) and sesquiterpene hydrocarbons $(27.47 \%)$. Other compounds such as thymol methyl ether, 3-Oxo-7,8-dihydro- $\beta$-ionol, and Hexahydrofarnesyl acetone were detected from the essential oils of H. juniperinus and F. brasiliensis, representing $0.76 \%$ and $1.16 \%$, respectively. A monoterpene hydrocarbon $\beta$-Phellandrene was detected in essential oils of $S$. anomala and an oxygenated monoterpenes 1-octen-3-ol acetate was detected in the oils of S. anomala and F. brasiliensis.

\section{Discussion}

Many liverworts are endemic to the southern hemisphere, including Oceania and South America [7]. In the Ecuador (South America), there are around 770 species of liverworts [1-3], of which about eleven species have been previously studied. Liverworts (Hepaticae) are a rich source of terpenoids and aromatic compounds [7]. In this research, chemical constituents of studied species of liverworts were mainly grouped into sesquiterpene hydrocarbons $(\mathrm{SH})$ and oxygenated sesquiterpenes (OS). Only one monoterpene hydrocarbon (MH) ( $\beta$-phellandrene) with RI 1023 was determined; below RI 1000, no compound was identified in any of the four species studied. However, in Frullania tamarisci of France [10], three compounds ( $\alpha$-pinene, 1-Octen-3-ol, and $\beta$-pinene) with RI below 1000 were identified, which would indicate that it is possible to isolate this type (MH) of compounds from liverworts.

Around the year 1991, Nagashima et al. [13] investigated terpenoids and aromatic compounds of seven Ecuadorian liverworts. In the spieces Frullania brasiliensis found in total two compounds, the sesquiterpenoids Arbusculin B and $\alpha$-Bisabolol, the relative abundance percentages are not mentioned. In our study, for species Frullania brasiliensis twenty-five compounds were identified, the main compound identified for this species was $\tau$-muurolol (32.14\%), that like the $\alpha$-Bisabolol is an oxygenated sesquiterpenes of formula $\mathrm{C}_{15} \mathrm{H}_{26} \mathrm{O}$.

Between 2006 and 2001 Bardón et al. [12] studied the nonvolatile compounds from Frullania brasiliensis of Argentina, achieving isolate and identify two eremophilanolides, 5-epidilatanolides A and B, as well as a new natural bibenzyl. In this same study, also were identified the nonvolatile compounds eudesmane-type sesquiterpene lactones nepalensolide $A$, nepalensolide B, (+)-frullanolide, and (+)-dihydrofrullanolide, hopanoid zeorin, four sterols stigmasta-4,22-dien-3,6-dione, stigmasta-4,22-dien-3-one, stigmasterol, and sitosterol, and a trace amount of atraric acid.

The principal constituents in H. juniperinus are bicyclogermacrene $(18.23 \%)$ and caryophyllene oxide $(15.29 \%)$. For this species, no previous chemical or phytochemical studies have been carried out. However, two Ecuadorian species of the genus Herbertus, H. acanthelius, and H. subdentatus, were previously studied by Nagashima et al. [13] in which identified isocuparene-type sesquiterpenoids as the major components.

In studies related with Ecuadorian liverwort Nagashima et al. $[13,18]$ report that the compounds 3,4-Dimethoxy-1-vinylbenzene, 2,4,5-trimethoxy-1-vinylbenzene and apigenin-7,4'-dimethylether were identified in Marchesinia brachiate. 1,4-Dimethylazulene was isolated from Plagiochila micropterys and Macrolejeunea pallescens. The major component of Marchantia plicata is marchantin A and pinguisane-type sesquiterpenoid is the major component in Plagiochila alternans.

In the Ecuadorian species, Noteroclada confluens Taylor Ludwiczuk et al. [19] determined that the major component with $49 \%$ is an unknown sesquiterpene alcohol (molecular ion $\mathrm{M}^{+} 222$ ), and that species also produced a large amount of bicyclogermacrene and an unidentified bibenzyl derivative (molecular ion $\mathrm{M}^{+}$344]. According to Ludwiczuk et al. the main compounds occurring in Symphyogyna brasiliensis Nees from Ecuador are Dihydroagarofurane (36.3\%) and $\delta$-selinene (20.6\%), these species also produced cascarilladiene, selina-4,7-diene, eudesma-5,7(11)-diene, Bicyclogermacrene, thujopsene, 
calarene, $\gamma$ - and $\delta$-cuprenene, $\beta$-cubebene, bourbon-7(11)-ene and trans-dauca-4(11),7-diene [19]. On the other hand, Costa et al. [17] determined that chemical profiles of lipophilic extracts of Syzygiella rubricaulis (Nees) Stephani are rich in sesquiterpenes. Regarding the species Leptoscyphus hexagonus and Syzygiella anomala, no previous studies have been carried out.

\section{Materials and Methods}

\subsection{Materials}

Dichloromethane and sodium sulfate anhydrous were purchased from Sigma-Aldrich. The standard of aliphatic hydrocarbons was purchased from CHEM SERVICE under the name of Diesel Range Organics Mixture \#2-GRO/DRO and with the code M-TPH6X4-1ML. Helium was purchased from INDURA, Ecuador. All chemicals were of analytical grade and used without further purifications.

\subsection{Plant Material}

The plant material of the four species was collected in "El Tiro", in the province of Loja (Southern Ecuador, latitude, $3^{\circ} 58^{\prime} 59^{\prime \prime} \mathrm{S}$; longitude, $79^{\circ} 08^{\prime} 05^{\prime \prime} \mathrm{W}$; the altitude ranged from $2800-3000 \mathrm{~m}$ a.s.l). The storage and transfer of the plant material were carried out in airtight plastic containers until they are hydrodistilled. The collection temperature was $14-16^{\circ} \mathrm{C}$ (ambient temperature), and the transfer temperature was $16-18{ }^{\circ} \mathrm{C}$, the pressure was approximately $80 \mathrm{KPa}$ (ambient pressure). Voucher specimens were deposited in the Herbarium of the Universidad Técnica Particular de Loja (HUTPL)-Bryophytes and lichen collection under the acquisition numbers AB-1299 for Frullania brasiliensis, AB-1300 for Herbertus juniperoideus, AB-1264 for Leptoscyphus hexagonus, AB-1301 for Syzygiella anomala. The identity of the plant material was confirmed by the curator of lichens and bryophytes, the mentioned herbarium.

\subsection{Volatile Compounds Isolation}

The volatile compounds isolation was realized from $1500 \mathrm{~g}$ of vegetal material of Frullania brasiliensis, $4029 \mathrm{~g}$ of Herbertus juniperoideus, $6045 \mathrm{~g}$ of Leptoscyphus hexagonus and $4874 \mathrm{~g}$ of Syzygiella anomala. The material was processed fresh, immediately after arriving at the laboratory, between 8 and $12 \mathrm{~h}$ after being collected. The plant material of each species was hydrodistilled for four hours using a Clevenger-type apparatus. Subsequently, each extract sample (essential oil) was dried over sodium sulfate anhydrous and was stored in sealed vials, protecting them from light at $4{ }^{\circ} \mathrm{C}$ until being used in the analysis [20].

\subsection{Gas Chromatography/Flame Ionization Detector (GC/FID)}

The analyses of the chemical composition of the essential oils were performed on an Agilent gas chromatograph (model $6890 \mathrm{~N}$ series) equipped with a flame ionization detector (FID). A nonpolar column DB-5ms (5\%-phenyl-methylpolyxilosane) $30 \mathrm{~m} \times 0.25 \mathrm{~mm}$, thickness $0.25 \mu \mathrm{m}$ was used. An automatic injector (series 7683) in split mode was used. The samples, $1 \mu \mathrm{L}$ of solution $(1 / 100$, $v / v$, essential oil/dichloromethane), were injected with a split ratio of 1:50. Helium was used as a carrier gas at $0.9 \mathrm{~mL} / \mathrm{min}$ in constant flow mode. The initial oven temperature was held at $50{ }^{\circ} \mathrm{C}$ for $3 \mathrm{~min}$, and then it was heated to $210^{\circ} \mathrm{C}$ with a ramp of $2.5^{\circ} \mathrm{C} / \mathrm{min}$, and the temperature was maintained for $3 \mathrm{~min}$ until the end. The injector and detector temperatures were of $210^{\circ} \mathrm{C}$ and $250^{\circ} \mathrm{C}$, respectively. The retention index (IR) of the compounds was determined based on the standard of aliphatic hydrocarbons, which were injected after the oils at the same conditions.

\subsection{Gas Chromatography/Mass Spectrometry (GC/MS)}

The GC/MS analyses were performed using an Agilent chromatograph coupled to a mass spectrometer (quadrupole) detector (model Agilent series 5973 inert). The spectrometer was operated at $70 \mathrm{eV}$, electron multiplier $1600 \mathrm{eV}$, scan rate: $2 \mathrm{scan} / \mathrm{s}$, and mass range: $40-350 \mathrm{~m} / \mathrm{z}$. It was provided 
with a computerized system MSD-Chemstation D.01.00 SP1. The same columns described in GC/FID section were used. The ion source temperature was set at $250{ }^{\circ} \mathrm{C}$. The identification of the oil components was based on a comparison of both mass spectrum data and relative retention indices with the published literature [21-23]. The relative amounts of individual components were calculated based on the GC peak area (FID response) without using a correction factor.

\section{Conclusions}

Volatile metabolites of Herbertus juniperoideus (Sw.) Grolle, Leptoscyphus hexagonus (Nees) Grolle, and Syzygiella anomala (Lindenb. \& Gottsche) Steph were qualitatively and quantitatively characterized for the first time, in addition to these three species of liverworts, volatile secondary metabolites of Frullania brasiliensis Raddi were studied. A total of sixty-seven compounds were identified, which were mainly grouped into sesquiterpene hydrocarbons and oxygenated sesquiterpenes. The major components were $\tau$-muurolol in F. brasiliensis, bicyclogermacrene in H. juniperoideus, Cabreuva oxide D in L. hexagonus and silphiperfola-5,7(14)-diene in S. anomala.

Author Contributions: Conceptualization, E.V. and Á.B.; methodology, K.G.; formal analysis, K.G. and J.R.; investigation, E.V., K.G.; data curation, O.T.; writing—original draft preparation, Á.B.; writing一review and editing, E.V. All authors have read and agreed to the published version of the manuscript.

Funding: This research received no external funding.

Acknowledgments: Financial support for this study was granted by the "Universidad Técnica Particular de Loja" (PROY_QUI_1237). We thank the Ministerio del Ambiente Ecuador for providing the "Autorización de Investigación Científica N-006-2014-IC-FLO-DPL-MA".

Conflicts of Interest: The authors declare no conflict of interest.

\section{References}

1. León-Yánez, S.; Gradstein, S.R.; Wegner, C. Hepáticas (Marchantiophyta) y Antocerotas (Anthocerotophyta) del Ecuador: Catálogo; Herbario QCA, Pontificia Universidad Católica del Ecuador: Quito, Ecuador, 2006.

2. Schäfer-Verwimp, A.; Lehnert, M.; Nebel, M. Contribution to the knowledge of the bryophyte flora of Ecuador. Phytotaxa 2013, 128. [CrossRef]

3. Gradstein, S.R.; Benitez, A. Liverworts New to Ecuador with Description of Plagiochila priceana sp. nov. and Syzygiella burghardtii sp. nov. Cryptogam. Bryol. 2017, 38, 335-348. [CrossRef]

4. Linde, J.; Combrinck, S.; Vuuren, S.V.; Rooy, J.V.; Ludwiczuk, A.; Mokgalaka, N. Volatile constituents and antimicrobial activities of nine South African liverwort species. Phytochem. Lett. 2016, 16, 61-69. [CrossRef]

5. Asakawa, Y.; Ludwiczuk, A.; Nagashima, F. Phytochemical and biological studies of bryophytes. Phytochemistry 2013, 91, 52-80. [CrossRef] [PubMed]

6. Asakawa, Y.; Ludwiczuk, A.; Nagashima, F. Chemical Constituents of Bryophytes: Bio-and Chemical Diversity, Biological Activity, and Chemosystematics; Springer: New York, NY, USA, 2013.

7. Nagashima, F.; Asakawa, Y. Terpenoids and Bibenzyls from Three Argentine Liverworts. Molecules 2011, 16, 10471-10478. [CrossRef]

8. Asakawa, Y.; Toyota, M.; von Konrat, M.; Braggins, J.E. Volatile components of selected species of the liverwort genera Frullania and Schusterella (Frullaniaceae) from New Zealand, Australia and South America: A chemosystematic approach. Phytochemistry 2003, 62, 439-452. [CrossRef]

9. Li, R.J.; Zhu, R.X.; Zhao, Y.; Morris-Natschke, S.L.; Chen, C.H.; Wang, S.; Zhang, J.Z.; Zhou, J.C.; Lou, H.X.; Lee, K.H. Two new cadinane-type sesquiterpenes from the Chinese liverwort Frullania serrata. Nat. Prod. Res. 2014, 28, 1519-1524. [CrossRef] [PubMed]

10. Pannequin, A.; Tintaru, A.; Desjobert, J.M.; Costa, J.; Muselli, A. New advances in the volatile metabolites of Frullania tamarisci. Flavour Fragr. J. 2017, 32, 409-418. [CrossRef]

11. Hashimoto, T.; Irita, H.; Yoshida, M.; Kikkawa, A.; Toyota, M.; Koyama, H.; Motoike, Y.; Asakawa, Y. Chemical constituents of the Japanese liverworts Odontoschisma denudatum, Porella japonica, P. acutifolia subsp. tosana and Frullania hamatiloba. J. Hattori Bot. Lab. 1998, 84, 309-314. 
12. Bardón, A.; Mitre, G.B.; Kamiya, N.; Toyota, M.; Asakawa, Y. Eremophilanolides and other constituents from the Argentine liverwort Frullania brasiliensis. Phytochemistry 2002, 59, 205-213. [CrossRef]

13. Nagashima, F.; Nishioka, E.; Kameo, K.; Nakagawa, C.; Asakawa, Y. Terpenoids and aromatic compounds from selected Ecuadorian liverworts. Phytochemistry 1991, 30, 215-217. [CrossRef]

14. Toyota, M.; Asakawa, Y. Volatile constituent of the liverwort chiloscyphus pallidus (mitt.) engel \& schuster. Flavour Fragr. J. 1994, 9, 237-240. [CrossRef]

15. Hashimoto, T.; Nakamura, I.; Tori, M.; Takaoka, S.; Asakawa, Y. Epi-neoverrucosane- and ent-clerodane-type diterpenoids and ent-2,3-secoaromadendrane- and calamenene-type sesquiterpenoids from the liverwort heteroscyphus planus. Phytochemistry 1995, 38, 119-127. [CrossRef]

16. Nagashima, F.; Sekiguchi, T.; Takaoka, S.; Asakawa, Y. Terpenoids and aromatic compounds from the New Zealand liverworts Plagiochila, Schistochila, and Heteroscyphus species. Chem. Pharm. Bull. 2004, 52, 556-560. [CrossRef] [PubMed]

17. Costa, D.P.; Amado-Filho, G.M.; Pereira, R.C.; Paradas, W.C.; Miyataka, H.; Okamoto, Y.; Asakawa, Y. Diversity of Secondary Metabolites in the Liverwort Syzygiella rubricaulis (Nees) Stephani (Jamesoniellaceae, Marchantiophyta) from Neotropical High Mountains. Chem. Biodivers. 2018, 15, e1800239. [CrossRef] [PubMed]

18. Nagashima, F.; Murakami, Y.; Asakawa, Y. Aromatic compounds from the Ecuadorian liverwort Marchesinia brachiata: A revision. Phytochemistry 1999, 51, 1101-1104. [CrossRef]

19. Ludwiczuk, A.; Nagashima, F.; Gradstein, R.S.; Asakawa, Y. Volatile components from selected Mexican, Ecuadorian, Greek, German and Japanese liverworts. Nat. Prod. Commun. 2008, 3, 133-140. [CrossRef]

20. Valarezo, E.; Rosales, J.; Morocho, V.; Cartuche, L.; Guaya, D.; Ojeda-Riascos, S.; Armijos, C.; González, S. Chemical composition and biological activity of the essential oil of Baccharis obtusifolia Kunth from Loja, Ecuador. J. Essent. Oil Res. 2015, 27, 212-216. [CrossRef]

21. Adams, R.P. Identification of Essential Oil Components by Gas Chromatography/Mass Spectrometry, 4th ed.; Allured Publishing Corporation: Carol Stream, IL, USA, 2007.

22. Mass Spectral Library (NIST/EPA/NIH); National Institute of Standards and Technology (NIST): Gaithersburg, MD, USA, 2005.

23. National Institute of Standards and Technology (NIST). Libro del Web de Química del NIST, SRD 69. In Base de Datos de Referencia Estándar del NIST Número 69; U.S. Secretary of Commerce: USA, 2019. Available online: https://webbook.nist.gov/chemistry/index.html.es (accessed on 10 January 2020).

(C) 2020 by the authors. Licensee MDPI, Basel, Switzerland. This article is an open access article distributed under the terms and conditions of the Creative Commons Attribution (CC BY) license (http://creativecommons.org/licenses/by/4.0/). 